\title{
The Cretan Script Family Includes the Carian Alphabet
}

\author{
Peter Z. Revesz $z^{1, a}$ \\ ${ }^{1}$ Department of Computer Science, University of Nebraska-Lincoln, Lincoln, NE, 68588, USA
}

\begin{abstract}
The Cretan Script Family is a set of related writing systems that have a putative origin in Crete. Recently, Revesz [11] identified the Cretan Hieroglyphs, Linear A, Linear B, the Cypriot syllabary, and the Greek, Old Hungarian, Phoenician, South Arabic and Tifinagh alphabets as members of this script family and using bioinformatics algorithms gave a hypothetical evolutionary tree for their development and presented a map for their likely spread in the Mediterranean and Black Sea areas. The evolutionary tree and the map indicated some unknown writing system in western Anatolia to be the common origin of the Cypriot syllabary and the Old Hungarian alphabet. This paper argues that the missing link may be some ancestor of the Carian alphabet because several Carian alphabet letters show an intermediate stage between the corresponding Cypriot syllabary signs and the Old Hungarian letters.
\end{abstract}

\section{Introduction}

In the study of ancient scripts, Crete plays a major role as the location of origin of three different types of scripts: Cretan Hieroglyphs, Linear A and Linear B [2, 7, 8, 17, 18]. Moreover, Arthur Evans already proposed the spread of these Cretan scripts to Cyprus because of their resemblance to the later Cypro-Minoan and Cypriot syllabaries.

Recently, Revesz [12] noted further resemblances of the Cretan scripts with the Greek, Old Hungarian (native 'Rovásírás') [4, 6, 12, 13, 15], Phoenician, South Arabic and Tifinagh alphabets. By using phylogenetic algorithms from bioinformatics [9], Revesz [12] gave, as shown in Fig. 1, a hypothetical evolutionary tree for all the above-mentioned scripts, which he collectively named the Cretan Script Family. He also illustrated the hypothetical spread of these scripts on a map of the Eastern Mediterranean and Black Sea areas. The evolutionary tree suggested that the Cypriot syllabary and the Old Hungarian alphabet had a common immediate ancestor, which was putatively located in western Anatolia, which seemed a likely place before a presumed split towards the northern Black Sea areas, where Hungarians are first mentioned in written history, and Cyprus in the Eastern Mediterranean.

Western Anatolia was strongly influenced by the Minoan culture. In the early and middle Bronze Age, Miletus was a Minoan colony. In the late Bronze Age, Miletus became a Carian city. By the $8^{\text {th }}$ century BC, Miletus came under Greek influence and itself established many colonies in the Black Sea region (Gabrielson et al. [5], Tsetskhladze [14]). The above historical outline suggests the following hypothesis:

\footnotetext{
à Corresponding author: revesz@cse.unl.edu
}

Minoan writing spread first to western Anatolia, where it influenced the development of the Carian alphabet $[1,16]$, which spread with Milesian and other Carian settlers to various native groups of people who lived at that time on the northern shores of the Black Sea. Early Hungarian tribes were either included among those groups of people or they acquired the writing when they arrived to the northern Black Sea region.

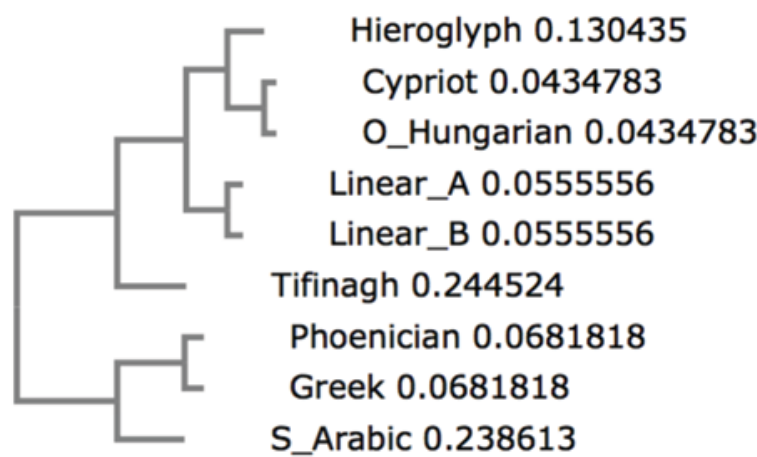

Fig. 1. The Cretan Script Family tree generated by the UPGMA phylogenetic algorithm (Revesz [12]) shows that Old Hungarian and Phoenician are in different branches of the tree. That suggests that Old Hungarian does not derive from Phoenician, and any similarity between these two alphabets is only due to their common origin.

Earlier alternative hypotheses regarding the origin of Old Hungarian include the Old Turkic (Orkhon) origin hypothesis by Sebestyén [13] and the Phoenician origin hypothesis elaborated in Hosszú [6]. More precisely, Hosszú [6] presents an encyclopedic study about Old Hungarian and its Steppean and Carpathian-Basin 
relatives, which collectively can be referred to as the Rovas group. (We do not deal with the members of this group separately because the differences among them seem relatively minor.) Chapter 4 of Hosszú [6] gives a genealogy or derivation of all Old Hungarian and related Rovas symbols from twenty Phoenician letters, four Old Turkic (Orkhon) ideograms and the Greek letter $\Phi$.

In contrast to Hosszú [6] and Sebestyén 13], our previous study (Revesz [12]) placed Old Hungarian and Phoenician in two separate branches of the Cretan Script Family. Hence any similarity of these two alphabets is only due to their common origin. Forrai [4] and Varga [15] also questioned the assumption that Old Hungarian derives from Phoenician or Old Turkic, but they did not specify a Cretan origin of Old Hungarian.

This paper is organized as follows. Section 2 describes a similarity function between pairs of script symbols. It also uses this function to place the Carian alphabet $[1,16]$ into a scripts comparison table (Table 1). Finally, Section 3 gives some conclusions and directions for future work.

\section{A Similarity Function for Symbol Pairs}

In this section, we present a modified version of the similarity function for pairs of script symbols given in Revesz [12]. Then we apply this modified function to the Carian alphabet [16]. That is, we place each Carian letter into Table 1 according to where it has the largest similarity to its Old Hungarian neighbor. The modified function is based on the following rules that give positive scores for various similarities between pairs of symbols.

Rule 1. If both symbols contain some curved lines or both symbols contain only straight lines, then the reward is one point.

Rule 2. If both symbols enclose some region or neither symbol encloses any region, then the reward is one point.

Rule 3. If both symbols contain slanted straight lines or neither symbols contains slanted straight lines, then the reward is one point.

Rule 4. If both symbols have two or more parallel lines, then they get a half point reward for each of the shared parallel lines.

Rule 5. If both symbols contain a cross $X$, then the reward is one point.

Rule 6. If both symbols contain a wedge $\wedge$ independent of any cross, then the reward is half point. If they both contain a wavy line (composed of repetitions of wedges), then the reward is one point.

Rule 7. If both symbols have similar sound values, then the reward is one point.

Rule 8. If both symbols have the same meaning, then the reward is one point.
The main modification in the above rules compared with those of Revesz [12] is that the scores given are now half of the scores given previously. In Rule 8 by 'have the same meaning' we mean that the two symbols depict the same object or action. Clearly, Rule 8 can be applied only in case the original object or action depicted by the symbol is not lost. Similarly, Rule 7 can be applied only in case the sound values of the symbols are both known.

The above set of rules gives us a scoring function $s(x, y)$ for any pair $x$ and $y$ of symbols. For example, let us find the similarity between the Carian letter $干_{\text {and the }}$ Old Hungarian letter $キ$. Both letters contain only straight lines (one point by Rule 1), neither symbol encloses any region (one point by Rule 2), neither symbol contains slanted straight lines (one point by Rule 3), the Carian letter has three and the Old Hungarian letter has two horizontal parallel lines, that is, they share two parallel lines (one point by Rule 4), both symbols contain a cross (one point by Rule 5). Rule 6 does not apply because neither letter has a wedge. The sound values of $/ \mathrm{j} /$ and $/ \mathrm{g} /$ are different but related. In fact, in many Proto-Ugric words that Khanty and Mansi, the closest language relatives of Hungarian, preserve with a / $\mathrm{j} /$ beginning has changed into a word with a $/ \mathrm{g} /$ beginning in Hungarian. This implies at least a partial score, let's say half point, by Rule 7 . Finally, we do not apply Rule 8 because it is not clear to us what objects the two letters are intended to depict. Hence by tallying up the scores, we obtain the following:

$$
\mathrm{s}(\text { 王,キ })=1+1+1+1+1+0+0.5+0=5.5
$$

which is a relatively high score. In fact, $\mathrm{s}\left(\boldsymbol{士}_{, \mathrm{x}}\right)<5.5$ for any other Old Hungarian symbol $x$. Hence $\underline{\mathbf{I}}_{\text {needs to be }}$ put into the table in the same row where $\neq$ is. The bestfit row for each of the other Carian letters can be found similarly. In general, this placement also fits well with the other symbols in the same row.

The most striking feature of Carian is that it is often the closest to Old Hungarian among all the other script symbols in a row. For example, consider the Old Hungarian $X / b /$. Comparing it with its Phoenician counterpart, we get:

$$
\mathrm{s}(\mathrm{X}, \boldsymbol{\Delta})=1+0+1+0+0+0+1+0=3
$$

Hosszú [6] and Sebestyén [13] assume the Orkhon $\mathbf{X} / \mathrm{b}$ to be the origin of the Old Hungarian $X / b /$. However, their similarity is only slightly higher:

$$
\mathrm{s}(\mathbf{X}, \mathbf{X})=1+0+1+0+1+0+1+0=4
$$

Note that the Carian 4 with phonetic value $/ \beta$ / (from Adiego [1], p. 229), which is a labial sound related to /b/, provides a similarly good alternative because

$$
s(X, 4)=0+1+1+0+1+0+1+0=4
$$


Table 1. A comparison of the symbols of the Cretan Hieroglyphs, Linear A, Linear B, Cypro-Minoan, Cypriot, Carian, Old Hungarina, Tifinagh, South Arabic, Phoenician, and Greek scripts. This table is modified from (Revesz [12]) mainly with the addition of the Carian alphabet. Next to each symbol in blue is its known phonetic value. Here 'unk' means the value is unknown.

\begin{tabular}{|c|c|c|c|c|c|c|c|c|c|c|}
\hline C. Hieroglyphs & $\begin{array}{c}\text { Linear } \\
\text { A }\end{array}$ & $\begin{array}{c}\text { Linear } \\
\mathrm{B}\end{array}$ & $\begin{array}{l}\text { Cypro- } \\
\text { Minoan } \\
\end{array}$ & Cypriot & Carian & $\begin{array}{c}\text { Old } \\
\text { Hungarian } \\
\end{array}$ & Tifinagh & $\begin{array}{l}\text { South } \\
\text { Arabic } \\
\end{array}$ & $\begin{array}{l}\begin{array}{l}\text { Phoeni } \\
\text { cian }\end{array} \\
\end{array}$ & Greek \\
\hline 等 & 9 & $P_{\mathrm{QA}}$ & & $\overline{\bar{Y}}_{\mathrm{KI}}$ & $\bar{P}_{K}$ & $\widehat{\Delta}_{\mathrm{K}}$ & $:: x$ & $\phi_{Q}$ & $\Phi_{\mathrm{Q}}$ & $\mathbf{Q}$ \\
\hline 8 & $\dot{x} p$ & $\mathrm{~T}_{\mathrm{A}}$ & & $X_{I} \Upsilon_{U}$ & $Y_{U}$ & 4 & & 高? & $K_{?}$ & A \\
\hline 马े & 为 & Át & & $x_{\mathrm{VA}}$ & $I_{1} I_{W}$ & $M_{\mathrm{U}, \mathrm{V}}$ & & & $Y_{W}$ & $Y$ \\
\hline $\mathbb{1}$ & $\varepsilon^{x} x^{x}$ & $\partial_{i_{\mathrm{KU}}}$ & 只 & $\mathrm{Q}_{\mathrm{RO}}$ & $\square_{E} \varphi_{Y}$ & Х欢 & & $\varphi_{H}$ & $\exists_{\mathrm{H}}$ & E \\
\hline 级 & 80 & $\left\llcorner_{\mathrm{RA}}\right.$ & & $\underline{\Omega}_{\mathrm{RA}}$ & $G_{R R}$ & $\partial_{\mathrm{N}}$ & $\mathrm{O}_{\mathrm{R}}$ & $\nu_{R}$ & $4_{R}$ & $\mathbf{P}$ \\
\hline$\uparrow \uparrow$ & $\uparrow$ & $\widehat{A}_{\mathrm{TI}}$ & A & $\uparrow_{\mathrm{TI}}$ & $\uparrow_{\mathrm{T}}$ & $\uparrow_{\mathrm{ts}}$ & $r_{s}$ & $\dot{\phi}_{\mathrm{r}}$ & $r_{s}$ & $M$ \\
\hline$\Delta$ & $\Delta \rightarrow$ & ${ }^{-}{ }_{I}^{-}$ & 4 & 个wo & $\theta_{\mathrm{I}}$ & $t_{\mathrm{I}} 1_{\mathrm{J}}$ & & $i_{J}$ & $z_{J}$ & I \\
\hline$\odot$ & $\odot$ & $\mathrm{O}_{\mathrm{QE}}$ & & $Q_{\mathrm{JA}}$ & $\phi_{\tilde{N}}$ & $\odot_{i} \boldsymbol{\theta}_{\lambda}$ & $\cdots \subseteq$ & ${ }^{\circ} \bar{G}$ & $\mathrm{O}_{\varsigma}$ & 0 \\
\hline ss & $k \Leftrightarrow$ & $\bigcup_{\mathrm{PTE}}$ & & $\underline{v}_{\mathrm{MI}}$ & $M_{P}$ & $\Varangle_{M}$ & $\bar{C}_{M}$ & $\mho_{M}$ & $m_{M}$ & M \\
\hline $\mathbb{U}$ & $\wedge Я$ & & $\Lambda$ & $\mathrm{V}_{\mathrm{SA}}$ & R d & $\Lambda$ & Бீ & 3 & $\mathbf{W}_{j}$ & $\Sigma$ \\
\hline W* & $Y$ & $F_{D A}$ & $F$ & $F_{\mathrm{TA}}$ & $<_{D}$ & $y$ & $V_{D}$ & $\Delta I_{D}$ & $\triangleleft_{D}$ & $\Delta$ \\
\hline$\Phi$ & & & & $\mathrm{X}_{\mathrm{MU}}$ & $\mathrm{Z}_{\mathrm{G}}$ & $\boldsymbol{\Delta}_{\mathrm{U}} \boldsymbol{X}_{\mathrm{X}}$ & $\Psi_{\mathrm{Z}}$ & $\mathrm{z}_{\mathrm{Z}}$ & $I_{Z}$ & $\mathbf{Z}$ \\
\hline 㱠 & $\nabla \overline{M^{3}}$ & $m_{\mathrm{KE}}$ & $M$ & $\aleph_{\mathrm{GA}}$ & $\overline{Z_{G}}$ & $\Lambda_{\mathrm{G}}$ & $Z_{G}$ & $7_{\mathrm{G}}$ & $1_{\mathrm{G}}$ & $\Gamma$ \\
\hline+ & + & $t_{\mathrm{RO}}$ & + & $t_{\mathrm{LO}}$ & $\boldsymbol{X}_{\text {unk }}$ & $t_{D}$ & $\boldsymbol{t}_{\mathrm{T}}$ & $\mathbf{X}_{\mathrm{T}}$ & $\mathbf{X}_{\mathrm{T}}$ & $T$ \\
\hline$\Leftrightarrow$ & 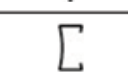 & $\overline{\mathrm{C}}_{\mathrm{TA}}$ & & Оि & $\Omega_{\mathrm{T}}$ & $\nu_{0}$ & & & & $\mathbf{\Omega}$ \\
\hline$w^{\nu}$ & $\zeta$ & $5_{\mathrm{PO}}$ & $\zeta$ & $\zeta_{\mathrm{PE}}$ & $\Gamma_{\mathrm{B}}$ & $\exists_{P}$ & & & $\gamma_{\mathrm{P}}$ & $\Pi$ \\
\hline & & & & & $\mathrm{T}_{\text {unk }}$ & $\mathrm{I}_{\mathrm{S}}$ & & & & \\
\hline$\sigma$ & 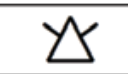 & $\overline{\bar{X}}$ NWA & ${ }^{\prime} n^{\prime}$ & $\underline{w}_{\mathrm{PU}}$ & $4_{\mathrm{MB}}$ & $\mathrm{X}_{\mathrm{B}}$ & $\breve{n}_{\mathrm{F}}$ & $\Pi_{\mathrm{B}}$ & $\boldsymbol{\Delta}_{\mathrm{B}}$ & B \\
\hline 必 & 74 & 275 & 11 & $7 r_{\mathrm{NO}}$ & & $\psi_{\mathrm{NT}}$ & $\dagger_{\mathrm{NT}}$ & $4_{N}$ & $4_{N}$ & $\mathbf{N}$ \\
\hline 28 & $\pi$ & $\overline{\Pi ె}_{\mathrm{PU}}$ & $\underline{1}$ & $\underline{L}_{\mathrm{LI}}$ & $\Delta_{\mathrm{L}}$ & $\bigwedge_{\mathrm{L}}$ & $\|_{L}$ & $1_{\mathrm{L}}$ & $L_{\mathrm{L}}$ & $\Lambda$ \\
\hline$\forall$ & $\mathrm{I}_{\mathrm{NE}} \overline{\mathrm{F}}$ & 非 $_{\mathrm{TE}}$ & & $\bar{F}_{\mathrm{TO}}$ & ${\overline{一_{J}}}_{\mathrm{J}}$ & $\neq_{\downarrow}$ & $E_{d l_{1}^{s}}$ & $x_{S}$ & $\mathbf{z}_{\mathrm{S}}$ & $\Xi$ \\
\hline 米 & 米 & $\mathrm{XY}_{\mathrm{NI}}$ & $\overline{\mathbf{T}}$ & $\overline{\overline{\mathrm{T}}}_{\mathrm{NA}}$ & $\psi_{N}$ & ${ }^{*} \overline{4}_{\mathrm{NAP}}$ & $\mathbf{I}_{\mathrm{N}}$ & & & \\
\hline$\varphi$ & 9 & $\mathrm{C}_{\mathrm{RU}}$ & H & )$\widehat{V}_{\mathrm{RU}}$ & $\mathrm{H}_{\lambda} \mathrm{C}_{\mathrm{R}}$ & $\mathrm{H}_{\mathrm{R}}$ & & & & \\
\hline 2 & 兗 & $\bar{\nabla}_{\mathrm{KI}}$ & & $\Psi_{\mathrm{KU}}$ & $\nabla_{\mathrm{K}}$ & $\mathcal{1}_{\mathrm{K}}$ & $\dot{\theta}_{\mathrm{K}}$ & $\mathbf{h}_{\mathrm{K}}$ & $\boldsymbol{X}_{\mathrm{K}}$ & $\mathbf{K}$ \\
\hline w & $\oplus$ & $\oplus \mathrm{KA}$ & 田 & Фмо & $\bigoplus_{\mathrm{Q}}$ & $\otimes_{\mathrm{F}}$ & $\left(D_{\mathrm{B}}\right.$ & $\Phi_{W} \diamond_{F}$ & & $\Phi$ \\
\hline$Y$ & $\psi$ & $\psi_{\mathrm{RE}}$ & & $y_{\mathrm{RI}}$ & $\Psi_{\text {unk }}$ & $\mathbf{Y}_{j>3}$ & & $\Psi_{\mathrm{H}}$ & & $\Psi$ \\
\hline$\varnothing$ & $\phi$ & & & & $D_{j}$ & $\mathbb{1}_{\mathrm{US}}$ & $\odot_{\mathrm{S}}$ & & & \\
\hline 四 & 田 & $\neq_{\mathrm{PA}}$ & $\neq$ & $\neq_{\mathrm{PA}}$ & $\Pi_{\mathrm{w}}$ & $\Pi_{\mathrm{U}}$ & & 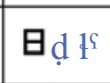 & 日 $_{\mathrm{H}}$ & H \\
\hline 好 & & $\mathbb{R}_{\mathrm{RA}}$ & $\hat{n}$ & $4_{z O}$ & $\mathbf{l}_{\delta}$ & $\boldsymbol{U}_{\mathrm{t}}, \mathbf{X}_{\mathrm{C}}$ & & $\mathbb{W}_{T^{s}}$ & $\boldsymbol{\otimes}_{T^{s}}$ & $\boldsymbol{\Theta}$ \\
\hline
\end{tabular}




\section{Conclusions and future work}

This paper identified the Carian alphabet as a script evolutionary missing link that was conjectured by Revesz [12] to have existed somewhere in western Anatolia as a common ancestor of the Cypriot syllabary and the Old Hungarian alphabet. That new identification greatly strengthens the Cretan Script Family hypothesis, that is, the idea that Crete is the origin a set of related scripts that spread throughout the eastern Mediterranean and the Black Sea regions in ancient times.

The more complete and improved understanding of the evolutionary tree of the Cretan Script Family has a bearing on the still continuing efforts to 'decipher' aka translate the unknown Cretan Hieroglyph and Linear A scripts, for it seems most fruitful to substitute for the symbols of these unknown scripts the phonetic values of the evolutionarily closest known scripts. Using that simple but essential idea, it has become possible to give some preliminary translations of the Phaistos Disk (also spelled Disc) [10], and some short Cretan Hieroglyph inscriptions [11].

It remains an outstanding open problem to carry on the translation work for other prominent Minoan texts such as the Malia Altar Stone inscription [3].

\section{References}

1. I.J. Adiego, The Carian Language, (Koninklijke Brill NV, Leiden, The Netherlands, 2007)

2. J. Chadwick, The Decipherment of Linear B, (Cambridge University Press, 1958)

3. F. Chapouthier, Inscription hiéroglyphique gravée sur un bloc de calcaire, Bulletin de Correspondance Hellénique 62, 104-109, (1938)

4. S. Forrai, The Old Hungarian Writing from Ancient Times to the Present, (in Hungarian), (Antológia Kiadó, Budapest, Hungary 1994)

5. V. Gabrielson, J. Lund, \& T. Madsen (Eds.), The Black Sea in Antiquity: Regional and Interregional Economic Exchanges, (Sandbjerg, Denmark: Oxbow Books 2007).

6. G. Hosszú, Heritage of Scribes: The Relation of Rovas Scripts to Eurasian Writing Systems, (Rovas Foundation Hungary, Budapest, Hungary 2013)

7. J.-P. Olivier, Cretan writing in the second millennium B.C., World Archaeology. 17, 3, 377389 (1986).

8. J.-P. Olivier, L. Godart and J.-C. Poursat, Corpus Hieroglyphicarum Inscriptionum Cretae Études Crétoises 31, (De Boccard, Paris 1996)

9. P.Z. Revesz, Proc. 4th ACM Int. Conf. on Bioinfo. and Comp. Bio., 731-734, (ACM Press, New York, USA, 2013)

10. P.Z. Revesz, A computer-aided translation of the Phaistos Disk, Int. Journal of Computers, 10, 94-100, (2016)
11. P.Z. Revesz, A computer-aided translation of the Cretan Hieroglyph script, Int. Journal of Signal Processing, 1, 127-133 (2016)

12. P.Z. Revesz, Bioinformatics evolutionary tree algorithms reveal the history of the Cretan script family, Int. Journal of Applied Mathematics and Informatics, 10, 67-76, (2016)

13. G. Sebestyén, Rovás és Rovásírás, (Magyar Néprajzi Társaság, 1909)

14. G. Tsetskhladze, (Ed.), The Greek Colonization of the Black Sea Area, (Franz Steiner, Stuttgart 1998)

15. G. Varga, Bronzkori Magyar Irásbeliség, (Irástörténeti Kutató Intézet, 1993)

16. Wikipedia, "Carian alphabets," downloaded April 5, 2017. Available: https://en.wikipedia.org/wiki/Carian_alphabets

17. J. G. Young, Minos 31-32 (1996-1997[1999]) 379400.

18. P. Yule, Early Cretan Seals: A Study of Chronology, Marburger Studien zur Vor und Frühgeschichte $\mathbf{4}$ (Mainz 1981) 